\title{
Micro-Raman and Micro-FT-IR Spectroscopic Investigation of Raw and Dyed Pan Fibers
}

\author{
Biljana Minčeva-Šukarova, ${ }^{\mathrm{a}, *}$ Biljana Mangovska, ${ }^{\mathrm{b}}$ Gordana Bogoeva-Gaceva, ${ }^{\mathrm{b}}$ \\ and Vladimir Mihail Petruševski ${ }^{a}$ \\ anstitute of Chemistry, Faculty of Natural Sciences and Mathematics, "Ss Cyril \& Methodius" University, Arhimedova 5, \\ P.O. Box 162, 1000 Skopje, Republic of Macedonia \\ ${ }^{\mathrm{b}}$ Faculty of Technology and Metallurgy, "Ss Cyril \& Methodius" University, Rudjer Bošković 16, \\ 1000 Skopje, Republic of Macedonia
}

RECEIVED MARCH 23, 2011; REVISED OCTOBER 17, 2011; ACCEPTED DECEMBER 5, 2011

\begin{abstract}
Micro-Raman and micro-FTIR spectroscopy were used to investigate raw and dyed polyacrylonitril (PAN) fibers with three different linear densities (3, 6 and 9 den), dyed with three cationic dyes (red, blue and yellow) by standard procedure. The Raman and the IR spectra of the raw and dyed fibers as well as the corresponding spectra of pure dyes were analyzed. High quality spectra, both Raman and IR were obtained, requiring no sample preparation. Dyed fibers gave Raman spectra with bands characteristic for both the polymer and the dyes, while the IR spectra consist of predominantly bands due to the fiber polymer. Spectral subtraction procedures were used to separate the Raman spectra of the raw PAN fiber from the corresponding spectrum of dyed fiber and were then compared with the Raman spectra of pure dyes. The recorded Raman spectra of the three different linear densities of dyed fibers did not show variation in band frequencies, but in one dyed (blue) fiber, a regular variation in the band intensities was observed. This effect has been related to the quantity of the dye fixed on the (blue) fiber in three different linear densities. The results were compared with the quantity of the absorbed dye, previously determined for the blue fiber by colorimetric measurements. (doi: 10.5562/cca1888)
\end{abstract}

Keywords: micro-Raman spectroscopy, micro-infrared spectroscopy, spectra subtraction, PAN fibers, dyed fibers

\section{INTRODUCTION}

Vibrational spectroscopy is one of the main tools for characterization of polymer matrixes and acrylic fibers. ${ }^{1}$ With the introduction of the microscopes in the spectroscopic techniques, such as micro-Raman and microinfrared ( $\mu$-Raman and $\mu$-IR from now on) spectroscopy, the characterization of fibers, both raw and dyed, became an important aspect of their application. The characterization of polymer-based fibers is important for forensic, industrial and other purposes. ${ }^{1-7}$ Raman and IR spectroscopic studies on fibers and dyed fibers showed that Raman data provided information about the dyes used in dyeing the fibers, but gave little information about the polymer, while IR spectra were found to be well suited for characterization of the polymer, but gave poor information on the dyes. ${ }^{8}$ Some Raman experiments on dyed fibers have shown that this technique enables identification of the main dye present in colored fiber, but the components of the dyes are much more difficult to detect ${ }^{9,10}$ because of their low overall content. Simultaneous application of both techniques could allow (in favorable cases) a characterization and identification of raw polymer-based fibers ${ }^{7}$ and also, in the case of dyed fibers, the type of the dye used. ${ }^{4,5,8}$

As a part of our spectroscopic study on synthetic ${ }^{11}$ and natural ${ }^{12}$ fibers, we analyzed raw and dyed PAN fibers (based on acrylonitrile copolymer containing 5.6 \% methacrylic acid and $1.7 \%$ itaconic acid - brand name Malon) by the means of $\mu$-Raman and $\mu$-IR spectroscopy.

Synthetic PAN fibers of Malon type, standard products of the OHIS (Organic and Chemical Industry company in Skopje - Republic of Macedonia), have specific features upon dyeing that are thoroughly studied and reported elsewhere. ${ }^{13-15}$ Of the Malon PAN fibers' characteristics, their dying parameters were determined, while the quantity of the dye on PAN fibers was examined by the extraction of the dye in DMF. ${ }^{15}$

In this paper, a combined $\mu$-Raman and $\mu$-IR study of PAN dyed fibers with three different linear densities

\footnotetext{
* Author to whom correspondence should be addressed. (E-mail: biljanam@pmf.ukim.mk)
} 


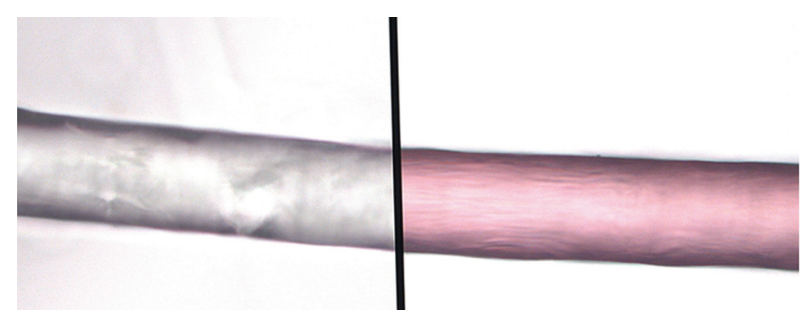

Figure 1. Raw and red dyed PAN fiber of linear density 9 den. Magnification on the comparative microscope: $\times 20$.

(3, 6 and 9 den), dyed with three cationic dyes (red, blue and yellow) by standard procedure 13-15 is reported. The $\mu$-Raman and $\mu$-IR spectra of these dyed fibers, raw fibers as well as the corresponding spectra of the dyes used for dyeing the fibers were recorded in the region $4000-100 \mathrm{~cm}^{-1}$ (4000-700 $\mathrm{cm}^{-1}$ for the IR spectra), and their peculiarities were discussed. Spectral subtraction procedure was used to separate the Raman spectra of raw PAN fibers from the corresponding spectra of dyed fibers, by which, Raman spectra of pure dyes were obtained. An attempt was made to distinguish the relative quantity of the blue dye absorbed by an appropriate fiber from the recorded Raman spectra of three different linear densities of blue dyed PAN fiber.

\section{EXPERIMENTAL}

\section{Samples-PAN Fibers (Raw and Dyed):}

PAN raw and colorless fibers - Malon type, with three different linear densities: 3 den $=3.3$ dtex $(18.87 \mu \mathrm{m}), 6$ den $=6.6$ dtex $(26.69 \mu \mathrm{m})$ and 9 den $=9.9$ dtex $(32.68$ $\mu \mathrm{m})$ were obtained from the manufacturer. The fibers were dyed with commercial product dyes: Bezacryl Blue GRL $300 \%$, Bezacryl Yellow GL $200 \%$ and Bezacryl Red GRL $180 \%$, all from Bezema, by standard methods. ${ }^{13}$ The red dyed fiber of linear density 9 den and the corresponding raw (undyed) PAN fiber, recorded on a comparative microscope, are presented on Figure 1.

\section{Raman Measurements}

$\mu$-Raman spectra (in the $4000-100 \mathrm{~cm}^{-1}$ region) were recorded on Horiba Jobin-Ivon LabRam300 spectrometer, equipped with He-Ne laser. The instrument operated at $633 \mathrm{~nm}$ with a power of $7 \mathrm{~mW}$ at the sample. An Olympus MPlaN microscope $(f \times 100$ objective $)$ with numerical aperture of 0.9 and working distance of 0.21 $\mathrm{mm}$ was used to focus the laser on the sample. The backscattered light was dispersed by using a grating of $1800 \mathrm{lines} / \mathrm{mm}$ and was detected on a multi-channel aircooled CCD detector. The exposure time was between 40 and $60 \mathrm{~s}$ and the instrumental resolution varied between 1 and $2 \mathrm{~cm}^{-1}$. Due to the very strong fluorescence, the blue fibers were recorded with NIR laser
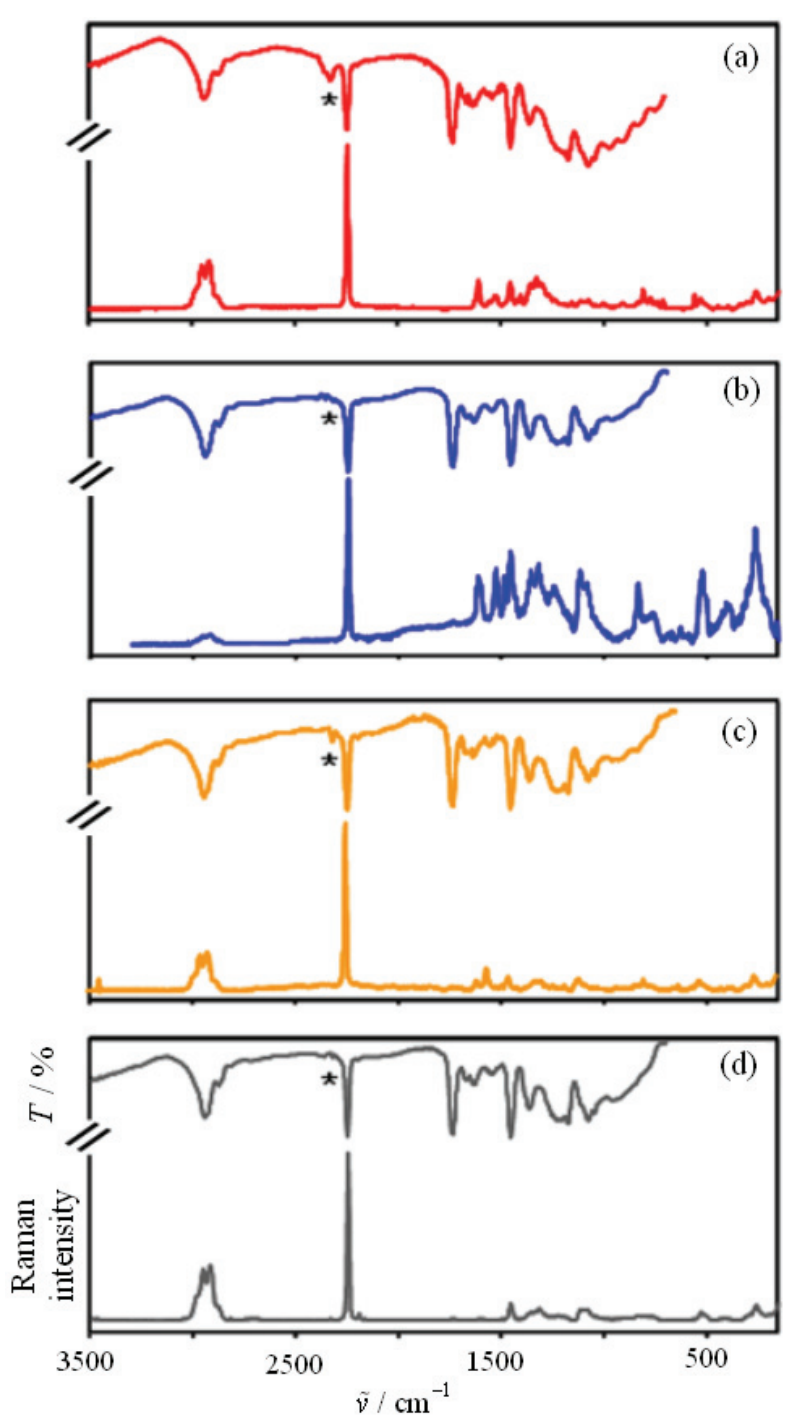

Figure 2. Raman and IR spectra of: (a) Red PAN fiber; (b) Blue PAN fiber; (c) Yellow PAN fiber and (d) Raw PAN fiber, in the spectral region $3500-150 \mathrm{~cm}^{-1}$. (Linear density: 9 den). (The weak band, due to uncompensated $\mathrm{CO}_{2}$ in the IR spectra, is marked with asterisk).

diode operating at $785 \mathrm{~nm}$ and on a LabRam HR800 spectrometer. In this case, a 600 lines $/ \mathrm{mm}$ grating was used, and with the $800 \mathrm{~mm}$ focal length, the resolution of $1 \mathrm{~cm}^{-1}$ per pixel was achieved.

The single PAN fibers were mounted on a microscope slide, tied up with scotch tape, placed under the microscope and exposed directly to the laser beam. Three measurements were obtained on each fiber from samples with three different linear densities. The Raman spectra of powder dyes were obtained as uncovered powder, and were placed directly on a microscopic slide. LabSpec software ${ }^{16}$ was used for data acquisition and GRAMS software ${ }^{17}$ for data manipulation. Spectral subtraction was performed using the GRAMS software package. ${ }^{17}$ 

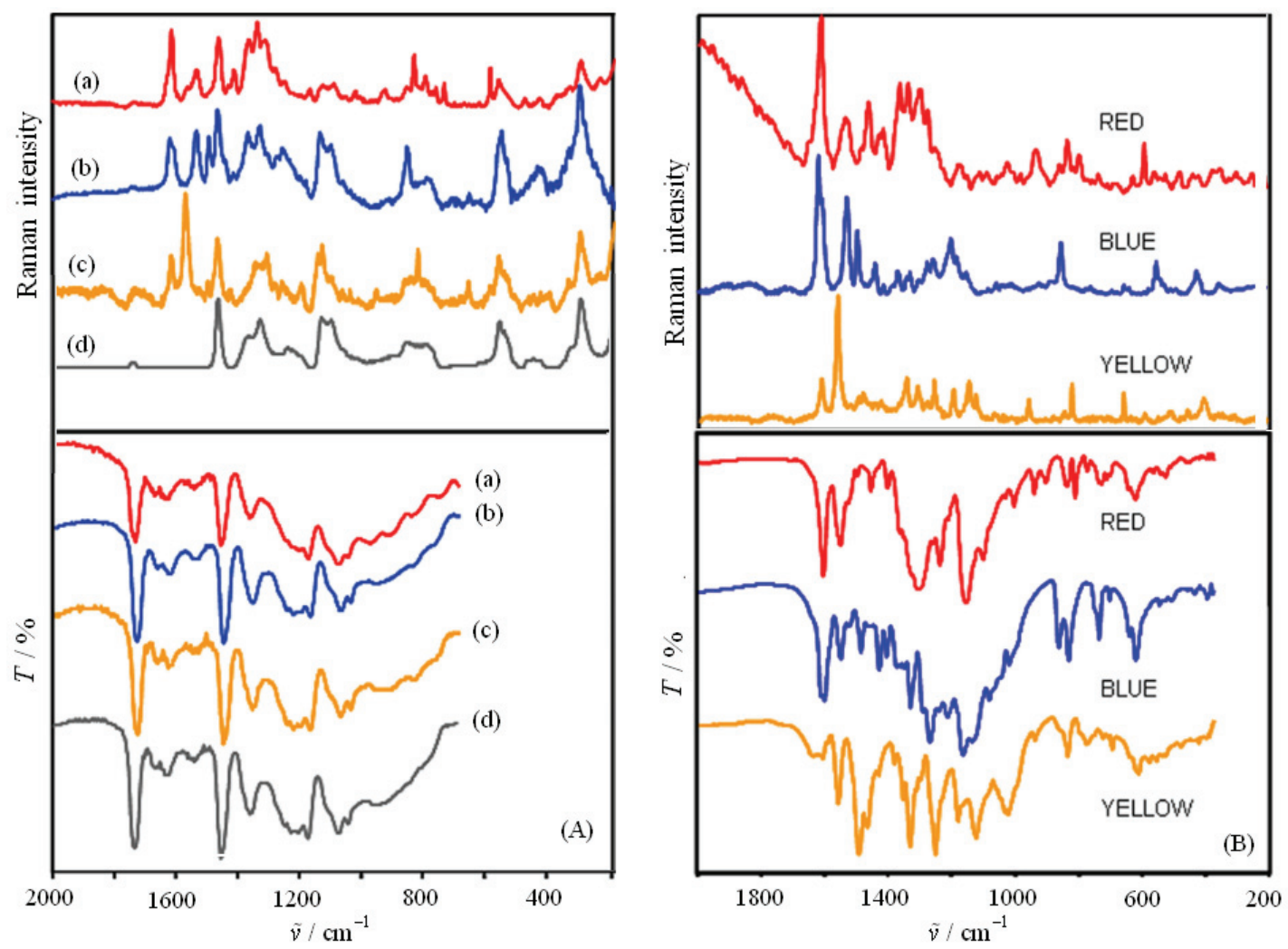

Figure 3. (A) Raman spectra (top diagrams) and IR spectra (bottom diagrams) of: (a) Red PAN fiber; (b) Blue PAN fiber; (c) Yellow PAN fiber; (d) Raw PAN fiber. (Linear density: 9den). (B) Raman spectra (top diagrams) and IR spectra (bottom diagrams) of the powder dyes: red (Bezacryl Red GRL 180 \%); blue (Bezacryl Blue GRL $300 \%$ ) and yellow (Bezacryl Yellow GL $200 \%$ ) dyes used for dying the PAN fibers.

\section{Infrared Measurements}

All $\mu$-IR spectra were recorded in the transmission mode on a Perkin-Elmer Spectrum 1000 FT-IR spectrometer with an AutoIMAGE FT-IR microscope system on fully automated focus stage with $10 \mu \mathrm{m}$ spatial resolution, scanning from 4000 to $700 \mathrm{~cm}^{-1}$. The fibers were placed directly under the microscope, 100 spectra were accumulated with the spectral resolution of $1 \mathrm{~cm}^{-1}$ at $3000 \mathrm{~cm}^{-1}$. The IR spectra of the dyes were obtained from powdered dye samples pressed into potassium bromide pellets and were recorded on Perkin-Elmer System 2000 interferometer, scanning from 4000 to 400 $\mathrm{cm}^{-1}$, with 64 scans and $3 \mathrm{~cm}^{-1}$ resolution.

\section{RESULTS AND DISCUSSION}

\section{Raman and IR Spectra of Raw and Dyed PAN Fibers}

The comparison between the IR and Raman spectra of dyed fibers and the corresponding raw fiber (linear density of 9 den), in $3500-150 \mathrm{~cm}^{-1}$ spectral region, are shown on Figure 2a-d. On Figure 3A, a series of Raman spectra (in the region $2000-100 \mathrm{~cm}^{-1}$ ) and IR spectra (in the region $2000-700 \mathrm{~cm}^{-1}$ ) of dyed fibers and a raw
PAN fiber (linear density of 9 den) are presented. The Raman (in the region $2000-100 \mathrm{~cm}^{-1}$ ) and IR spectra (in the region $2000-400 \mathrm{~cm}^{-1}$ ) of powdered dyes are presented on Figure 3B.

As seen from Figure 3A, the Raman spectra of dyed fibers show bands characteristic for both the polymer and the dyes and the IR spectra consist of predominantly bands due to the PAN fiber polymer. While the IR spectra of dyed and raw PAN fiber are very similar (Figure $3 \mathrm{~A}$ - bottom diagrams), there is a clear distinction between the Raman spectra of dyed and the raw PAN fiber (Figure 3A - top diagrams). The Raman spectra of pure powdered dyes (red, blue and yellow) (Figure 3B - top diagrams) are comparable with the corresponding spectra of dyed fibers (Figure 3A - upper frame); while that is not the case with the IR spectra of pure dyes and the corresponding spectra of dyed PAN fibers (Figure $3 \mathrm{~B}$ and Figure $3 \mathrm{~A}$ - bottom diagrams). Tentative assignments of the Raman and IR bands in the $3000-1000 \mathrm{~cm}^{-1}$ spectral region for the three dyed fibers and the corresponding raw PAN fiber are given in Table 1.

Following are few key comments concerning the assignments:

$C-H$ stretching vibrations: The bands due to aliphatic $\mathrm{C}-\mathrm{H}$ stretching vibrations appear just below $3000 \mathrm{~cm}^{-1}$ 
Table 1. Tentative assignment of some of the Raman and IR bands of raw and dyed fibers in $3000-1000 \mathrm{~cm}^{-1}$ spectral region

\begin{tabular}{|c|c|c|c|c|c|c|c|c|}
\hline \multicolumn{4}{|c|}{ Raman } & \multicolumn{4}{|c|}{ Infrared } & \multirow{2}{*}{ Assignment } \\
\hline Red & Blue & Yellow & Raw & Red & Blue & Yellow & Raw & \\
\hline $2949 \mathrm{~m}$ & $2949 \mathrm{~m}$ & $2950 \mathrm{~m}$ & $2949 \mathrm{~m}$ & - & $2938 \mathrm{~s}$ & $2936 \mathrm{~s}$ & $2934 \mathrm{~s}$ & $\mathrm{CH}$ aliphatic stretching \\
\hline $2914 \mathrm{~m}$ & $2914 \mathrm{~m}$ & $2913 \mathrm{~m}$ & $2914 \mathrm{~m}$ & $2870 \mathrm{~m}$ & $2870 \mathrm{~m}$ & $2877 \mathrm{~m}$ & $2872 \mathrm{sh}$ & \\
\hline 2242 vs & 2243 vs & 2243 vs & 2243 vs & 2242 vs & 2242 vs & 2242 vs & 2243 vs & ${ }^{12} \mathrm{CN}$ stretching \\
\hline $2191 \mathrm{vw}$ & - & $2192 \mathrm{vw}$ & $2191 \mathrm{vw}$ & $2192 \mathrm{vw}$ & $2192 \mathrm{vw}$ & $2193 \mathrm{vw}$ & $2190 \mathrm{vw}$ & ${ }^{13} \mathrm{CN}$ stretching \\
\hline \multirow[t]{2}{*}{$1733 \mathrm{vw}$} & $1733 \mathrm{vw}$ & $1731 \mathrm{vw}$ & $1732 \mathrm{vw}$ & 1734 vs & 1734 vs & 1732 vs & 1734 vs & $\mathrm{C}=\mathrm{O}$ stretching (esteric) \\
\hline & & & & $\begin{array}{l}1667 \mathrm{~m} \\
1629 \mathrm{~m}\end{array}$ & $\begin{array}{l}1670 \mathrm{~m} \\
1626 \mathrm{~m}\end{array}$ & $\begin{array}{l}- \\
-\end{array}$ & $\begin{array}{l}1666 \mathrm{w} \\
1624 \mathrm{w}\end{array}$ & $\begin{array}{l}\mathrm{C}=\mathrm{O} \text { stretching (acidic, } \\
\text { strongly } \mathrm{H} \text {-bonded) }\end{array}$ \\
\hline $1620 \mathrm{sh}$ & $1614 \mathrm{~m}$ & $1608 \mathrm{~m}$ & - & & & & & C-C stretching \\
\hline $1607 \mathrm{~m}$ & $1601 \mathrm{w}$ & $1561 \mathrm{w}$ & - & & & & & \\
\hline $1557 \mathrm{w}$ & & & - & & & & & \\
\hline $1521 \mathrm{w}$ & $\begin{array}{l}1527 \mathrm{w} \\
1486 \mathrm{~m}\end{array}$ & $1488 \mathrm{w}$ & $\begin{array}{l}- \\
-\end{array}$ & & & & & $\begin{array}{l}\mathrm{C}-\mathrm{C} \text { stretching } \\
\text { (aromatic dye) }\end{array}$ \\
\hline $1453 \mathrm{~s}$ & $1456 \mathrm{~s}$ & $1456 \mathrm{~s}$ & 1454 vs & $1451 \mathrm{vs}$ & 1454 vs & 1451 vs & 1450 vs & $\mathrm{CH}_{2}$ bending (scissoring) \\
\hline $1423 \mathrm{w}$ & $1431 \mathrm{sh}$ & & - & & & & & \\
\hline $1403 \mathrm{~m}$ & $1405 \mathrm{w}$ & $1414 \mathrm{w}$ & $\begin{array}{l}- \\
-\end{array}$ & & & & & $\mathrm{C}-\mathrm{C}$ stretching (aromatic dye) \\
\hline $1352 \mathrm{~m}$ & $1355 \mathrm{~m}$ & - & $1357 \mathrm{~m} \mathrm{sh}$ & $1360 \mathrm{~m}$ & $1358 \mathrm{~s}$ & $1361 \mathrm{~m}$ & $1361 \mathrm{~m}$ & $\mathrm{CH}_{3}$ bending (umbrella) \\
\hline $1325 \mathrm{~m}$ & $1317 \mathrm{w}$ & $1330 \mathrm{sh}$ & $1316 \mathrm{~m}$ & & & & & \\
\hline 1302 br & $1290 \mathrm{br}$ & $1295 \mathrm{w}$ & - & & & & & Vibrations of aromatic dye \\
\hline $1266 \mathrm{sh}$ & $1261 \mathrm{w} \mathrm{sh}$ & $1264 \mathrm{w}$ & - & & & & & (assignment uncertain due to \\
\hline \multirow[t]{2}{*}{$1235 \mathrm{sh}$} & $1242 \mathrm{w}$ & $1242 \mathrm{w}$ & - & & & & & unknown composition) \\
\hline & & $1183 \mathrm{~m}$ & - & $\begin{array}{l}1216 \mathrm{br} \\
1170 \mathrm{~s}\end{array}$ & $\begin{array}{l}1216 \mathrm{sh} \mathrm{s} \\
1170 \mathrm{~s}\end{array}$ & $\begin{array}{l}1216 \mathrm{br} \\
1169 \mathrm{sh} \mathrm{s}\end{array}$ & $\begin{array}{l}1216 \text { br s } \\
1170 \mathrm{~s}\end{array}$ & $\begin{array}{l}\mathrm{C}-\mathrm{O} \text { stretching (acidic, } \\
\text { upper and esteric, lower) }\end{array}$ \\
\hline \multirow[t]{2}{*}{$1120 \mathrm{w}$} & $1120 \mathrm{w}$ & $1126 \mathrm{~m}$ & - & & & & & $\begin{array}{l}\mathrm{CH} \text { in-plane bending } \\
\text { (aromatic dye) }\end{array}$ \\
\hline & $1085 \mathrm{~m}$ & $\begin{array}{l}1113 \mathrm{~m} \\
1083 \mathrm{w}\end{array}$ & $\begin{array}{l}1114 \mathrm{~m} \\
1083 \mathrm{~m}\end{array}$ & $\begin{array}{l}1115 \mathrm{sh} \\
1072 \mathrm{~m} \\
1038 \mathrm{~m}\end{array}$ & $\begin{array}{l}1115 \mathrm{sh} \\
1074 \mathrm{~m} \\
1034 \mathrm{~m}\end{array}$ & $\begin{array}{l}1115 \mathrm{sh} \\
1072 \mathrm{~m} \\
-\end{array}$ & $\begin{array}{l}1115 \mathrm{sh} \\
1071 \mathrm{w} \\
1038 \mathrm{w}\end{array}$ & $\begin{array}{l}\text { Raw PAN fiber, fingerprint } \\
\text { region (assignment uncertain) }\end{array}$ \\
\hline
\end{tabular}

$\mathrm{s}=$ strong; $\mathrm{m}=$ medium; $\mathrm{w}=$ weak $\mathrm{v}=$ very $; \mathrm{sh}=$ shoulder $\mathrm{br}=$ broad

and can safely be attributed to the $\mathrm{CH}_{3}$ and $\mathrm{CH}_{2}$ groups in the structure of the polymer (Figure 2). No bands due to aromatic $\mathrm{C}-\mathrm{H}$ stretching vibrations are detected both in the Raman and IR spectra of the dyed fibers, although some weak bands in th IR spectra of pure dyes are present in the region just above $3000 \mathrm{~cm}^{-1}$. This could probably be explained by the very low concentration of the dyes adsorbed/fixed on a raw PAN fibers and is in line with the above mentioned fact concerning the similarity of the IR spectra of all fibers (dyed and raw).

$C N$ stretching region: The band due to stretching $\mathrm{C} \equiv \mathrm{N}$ vibrations from the raw PAN fiber appears as a sharp and strong band at $2242 \mathrm{~cm}^{-1}$ in the Raman and IR spectra of both raw and dyed fibers (Figure 2 and Table 1). Its ${ }^{13} \mathrm{C}$ isotope counterpart appears (almost exactly at the fre- quency predicted using the simple model for a diatomic harmonic oscillator) as a weak band at $2192 \mathrm{~cm}^{-1}$ (calculated value is $2195 \mathrm{~cm}^{-1}$ ) in both Raman and IR spectra (Figure 2 and Table 1).

$C=O$ stretching region - some peculiarities: The band due to $\mathrm{C}=\mathrm{O}$ stretching vibration appears as a strong band in the IR spectra at $1733 \mathrm{~cm}^{-1}$, both in raw and dyed fibers (Figure $3 \mathrm{~A}$ - bottom diagram and Table 1) while the corresponding Raman band is very weak (Figure 3A - top diagram and Table 1). It can safely be attributed to the carbonyl stretch of the $\mathrm{C}-\mathrm{CO}-\mathrm{OCH}_{3}$ (ester) group from the PAN polymer. Two more bands at $\approx 1670$ and $1625 \mathrm{~cm}^{-1}$ ( $c f$. Table 1 ) deserve attention, despite their medium intensity. These two bands have been attributed to $\mathrm{C}=\mathrm{O}$ stretching (acid) vibration, alt- 
hough their frequencies are rather low for a carboxylic $\mathrm{C}=\mathrm{O}$ group, their intensity being low too. One possible explanation might be due to a change of the bonding in the $\mathrm{C}=\mathrm{O}$ group from covalent to partly ionic. Such low frequencies could also be explained by the assumption that the carboxylic group participates in very strong hydrogen bonding. Due to the strong hydrogen bonding, the bond order of the carbonyl group is expected to decrease, thus decreasing the vibrational frequency and that of the $\mathrm{C}-\mathrm{O}$ bond to increase (the corresponding frequency should increase slightly). If the latter explanation is the true, then the $\mathrm{OH}$ stretching vibration could be expected to be very low (centered at $\approx 1200 \mathrm{~cm}^{-1}$, somewhat higher or lower), very broad and structured, often with few transmission windows due to Evans type resonance (Evans effect). ${ }^{18}$ This peculiarity will be discussed in some detail below.

Aromatic $C-C$ stretching from the dye: The Raman bands in the $1620-1490 \mathrm{~cm}^{-1}$ region and in the $1430-1400 \mathrm{~cm}^{-1}$ region are most probably due to the organic dye, since they are present only in the spectra of dyed fibers, but not in a raw PAN fiber (Table 1). Due to the unknown composition of the aromatic dyes, the assignment of the Raman bands, appearing only in the spectra of the dyes, in the $1300-1240 \mathrm{~cm}^{-1}$ region (Figure $3 \mathrm{~A}$ - top diagram and Table 1), is uncertain.

$\mathrm{CH}_{2} / \mathrm{CH}_{3}$ bending vibrations: In the spectral region between 1450 and $1300 \mathrm{~cm}^{-1}$, both in the Raman and IR spectra, the bending vibrations from $\mathrm{CH}_{2}$ and $\mathrm{CH}_{3}$ groups are observed (Figure 3A). The strong band at $\approx 1450 \mathrm{~cm}^{-1}$ appears both in Raman and IR spectra and is undoubtedly due to $\mathrm{CH}_{2}$ scissoring while, medi$\mathrm{um} / \mathrm{strong}$ band at around $1360 \mathrm{~cm}^{-1}$ is most probably due the $\mathrm{CH}_{3}$ anti symmetric bending mode (Figure 3A and Table 1).

Spectral region between $1200-1000 \mathrm{~cm}^{-1}$ : Numerous IR and few Raman bands exist in this part of the spectrum (Figure 3A). At least some of them are due to $\mathrm{C}-\mathrm{C}$ skeletal stretching vibrations (originating from PAN fibers ${ }^{19}$ ). These bands are superimposed on a broad absorption that is probably due to the $\mathrm{OH}$ stretching vibration of the $-\mathrm{COOH}$ groups. This notion is strongly supported by the IR transmission windows at about $1300 \mathrm{~cm}^{-1}$ and $1100 \mathrm{~cm}^{-1}$ (Figure 3A bottom diagram). Such windows (Evans holes) are a characteristic feature of strongly hydrogen bonded systems. ${ }^{20}$ If this is true, i.e. if the carboxylic group is really strongly hydrogen bonded, the assignment of the other bands in this region may be very complicated (if not impossible), due to the strong vibrational coupling. In other words, the approximation for group vibrational frequencies (i.e. vibrations that are located in certain molecular fragment and are independent of the other part of the molecule) may not be valid anymore. For the above reason (strong vibrational coupling, altering the form of the normal
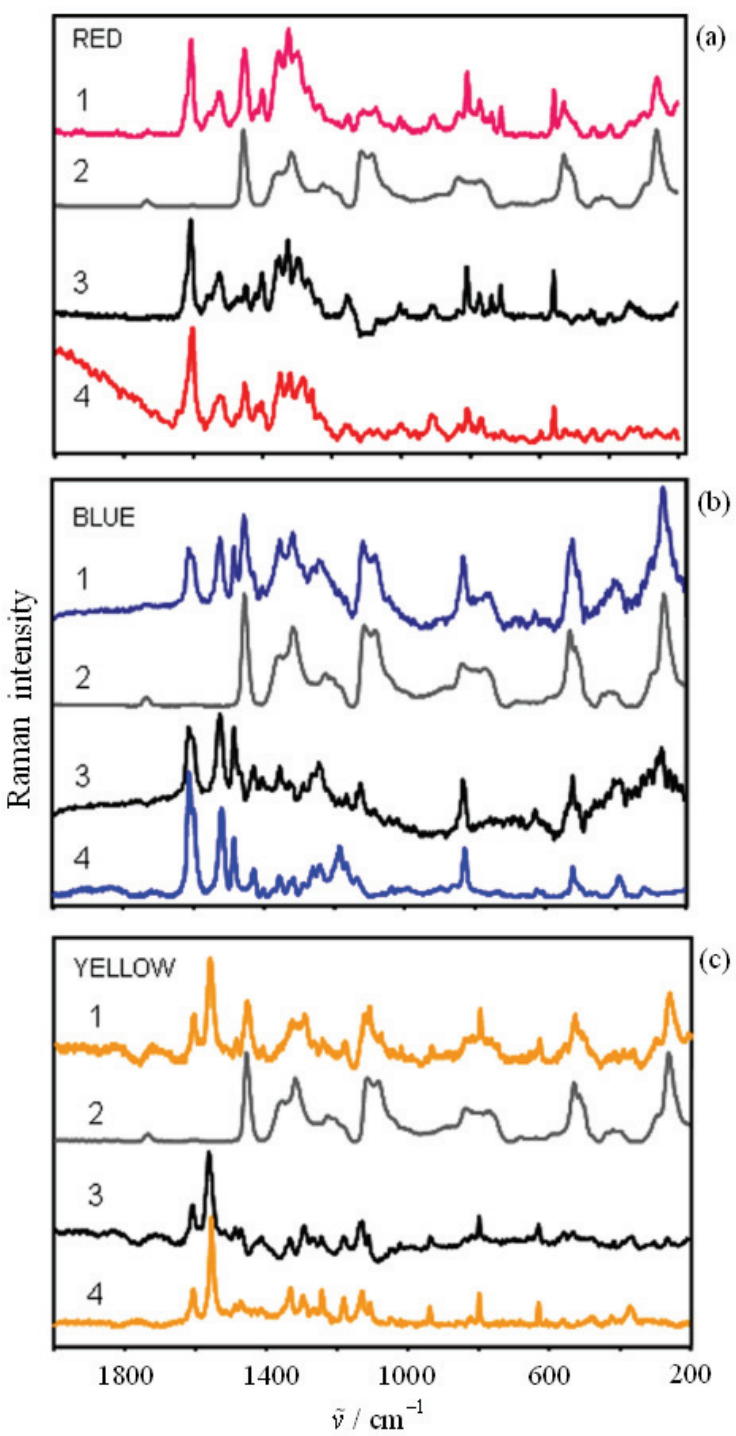

Figure 4. The results from the spectra subtraction (in the spectral region $2000-200 \mathrm{~cm}^{-1}$ ) for the red, blue and yellow PAN fibers (Linear density: 9 den). Legend: 1) Dyed PAN fiber; 2) Raw PAN fiber; 3) Result obtained after the subtraction of spectrum (1) - spectrum (2); 4) Raman spectrum of the corresponding pure dye.

modes), the assignment of the $\mathrm{C}-\mathrm{O}$ stretching mode in Table 1 should be considered as tentative only.

\section{Raman Spectral Subtraction Procedure}

As already stated in the literature, $\mu$-Raman technique has proved to be useful for studying dyes in fibers even if the nature of fiber polymer is not known., ${ }^{4,8}$ In our case the nature of the fiber polymer (PAN-Malon fibers) is known, but the powder dyes used for dying the fibers available from the manufacturer, were supplied only under their commercial names without any data about their structure. 
Table 2. Concentration of Bezacryl Blue GRL $300 \%$, Bezacryl Red GRL $180 \%$ and Bezacryl Yellow GL $200 \%$ and relative intensity of the Raman band due to the $\mathrm{C}=\mathrm{C}$ stretching vibration in the three different densities of the studied fibers: blue, red, and yellow

\begin{tabular}{|c|c|c|c|c|c|}
\hline Type of dyed fiber & Linear density (den) & $d / \mu \mathrm{m}$ & \multicolumn{2}{|c|}{$C_{\text {dye }} / \mathrm{g} / \mathrm{kg}^{(\mathrm{a})}$} & $I_{\text {rel }}\left(1614 \mathrm{~cm}^{-1}\right)^{(\mathrm{b})}$ \\
\hline & 9 & 32.68 & 1.45 & & 0.407 \\
\hline \multirow[t]{3}{*}{ Blue } & 6 & 23.69 & 1.50 & (Error: $14 \%$ ) & 0.502 \\
\hline & 3 & 18.87 & 1.65 & & 0.888 \\
\hline & 9 & 32.68 & 5.00 & & 0.190 \\
\hline \multirow[t]{3}{*}{ Red } & 6 & 23.69 & 5.20 & (Error: $16 \%$ ) & 0.257 \\
\hline & 3 & 18.87 & 5.80 & & 0.153 \\
\hline & 9 & 32.68 & 4.80 & & 0.026 \\
\hline \multirow[t]{2}{*}{ Yellow } & 6 & 23.69 & 5.50 & (Error: $25 \%$ ) & 0.025 \\
\hline & 3 & 18.87 & 6.00 & & 0.057 \\
\hline
\end{tabular}

(a) Results from colorimetric measurements of the extracted dye in DMF.

(b) Normalized on the $2242 \mathrm{~cm}^{-1}$ (the CN stretching Raman band).

In order to test the possibility of retrieving the spectrum of the dye from the dyed fiber, the spectral subtraction procedure was used; the Raman spectrum of the raw PAN fiber of 9 den was subtracted from the spectra of dyed fibers (red, blue and yellow) of the same linear densities and the obtained spectrum was then compared with the recorded Raman spectra of the corresponding pure dye. The results for the thickest fibers $(9$ den) are shown in Figures $4 \mathrm{a}-\mathrm{c}$ in the spectral region 2000 to $200 \mathrm{~cm}^{-1}$. As shown in Figures $4 \mathrm{a}-\mathrm{c}$, the Raman spectra of the three dyes (red, blue and yellow) obtained by Raman spectral subtraction procedure are very similar to the corresponding Raman spectra of the pure dyes. In some cases (e.g. the yellow dye and its corresponding subtracted spectrum), the Raman spectra are practically identical (Figure 4 for the yellow fibers).

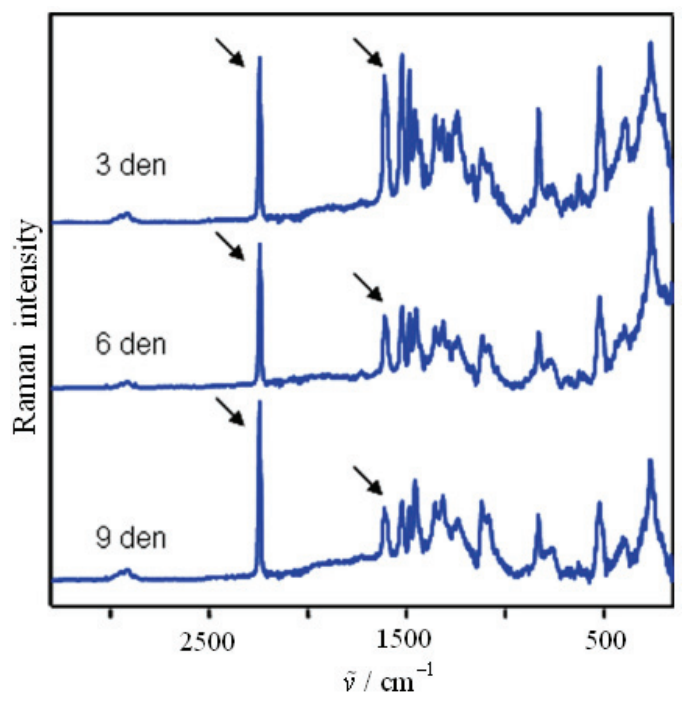

Figure 5. Raman spectra of the three linear densities of blue fibers (recorded using the $785 \mathrm{~nm}$ laser line). Each spectrum is normalized on the $2242 \mathrm{~cm}^{-1}$ band due to the $\mathrm{CN}$ stretching mode.

\section{The Quantity of Adsorbed (fixed) Dye on a Raw PAN Fiber}

In our previous studies on raw and dyed PAN fibers, some parameters connected with the dye fixed on fibers were determined by colorimetric measurements. ${ }^{15}$ An attempt was made in this study to characterize quantitatively the absorbed (fixed) dye on dyed PAN fibers with three different densities, from the Raman spectral data. For this purpose, only the analyses made on blue dyed PAN fibers with 3, 6 and 9 den showed satisfactory results and are in line with the previous colorimetric measurements for these dyed fibers.

As seen from Figure 5, differences in the relative intensities of the $\mathrm{CN}$ stretching band and the band at around $1614 \mathrm{~cm}^{-1}$ in three different densities of the blue fiber (shown with arrows on Figure5) can be observed. To simplify the procedure, the Raman spectra were normalized on the $2242 \mathrm{~cm}^{-1}$ Raman band (due to the $\mathrm{CN}$ stretching vibration) and this now has a unit height. In order to estimate the quantity of dye fixed on a PAN fiber with three different densities, the peak height of the band due to $\mathrm{C}=\mathrm{C}$ stretching (originating from the aromatic blue dye) was measured for all three thicknesses of dyed fibers. Note that due to $I_{2242}=1$ (consequence of normalization), the ratio of $I_{1614} / I_{2242}$ is simply equal to $I_{1614}$. The values for each blue fiber density are presented in Table 2, together with the previously determined quantity of the absorbed dye determined from the colorimetric measurements on these fibers. ${ }^{15}$ As seen from Table 2, (from both types of measurements, colorimetric, as well as from the Raman spectra) the thinnest blue fiber ( 3 den) absorbs the highest quantity of the dye (Figure 6).

However, the results for the red and yellow PAN dyed fibers (of all three linear densities) are not in line with the colorimetric measurements, most probably as a result of the large error in determining the concentrations of the adsorbed dye in the case of yellow and red 


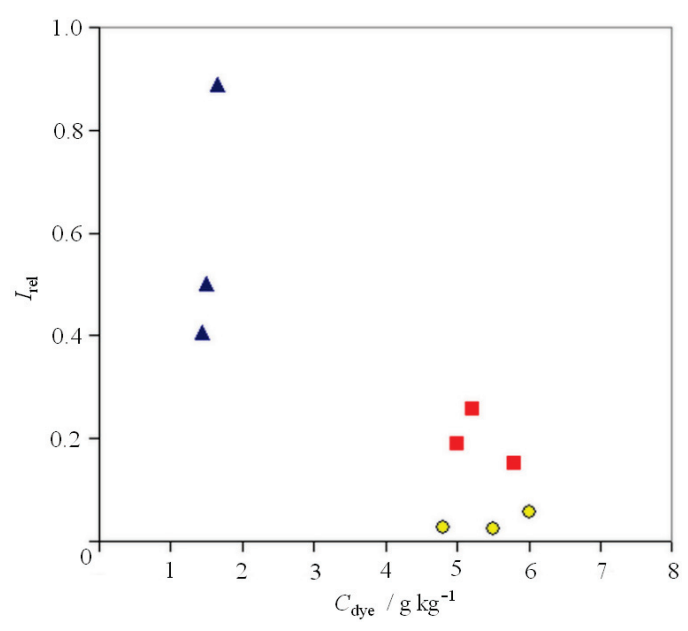

Figure 6. Relative Raman intensities (of $1614 \mathrm{~cm}^{-1}$ band) (normalized on the $2242 \mathrm{~cm}^{-1}$ band) as a function of the dye concentration in blue $(\Delta)$, red $(\square)$ and yellow $(\bullet)$ PAN fibers.

fibers (cf. Table 2 and Figure 6). At present, it is not quite clear what are the sources to these pronounced uncertainties in the two latter cases; it will remain a subject of our further investigation.

\section{CONCLUSIONS}

The results obtained from the investigation of the recorded Raman and IR spectra enabled assignment of the characteristic Raman and IR bands (in the spectral region 3000-1000 $\mathrm{cm}^{-1}$ ) for both PAN raw and dyed fibers. The IR spectra of the dyed PAN fibers were mainly dominated by the bands due to the fiber polymer, while the Raman spectra showed both the bands due to the dyes and the polymer.

A spectral subtraction procedure was used to separate the Raman spectra of dye from the corresponding spectrum of dyed fiber and was then compared with the Raman spectra of pure dyes. The spectra obtained in this way gave results that were more than satisfactory. The results obtained by this method prove that the Raman spectral subtraction procedure could be successfully applied for dye identification, providing that the user has a spectral database of common dyes at a disposal.

The Raman bands of the recorded Raman spectra of the three different linear densities of dyed fibers did not show significant variation in frequencies, but did show variation in the intensities. An attempt was made to compare the quantity of dye fixed on the fiber in three different linear densities from the Raman spectral data, by estimating the quantity of dye fixed on a PAN fiber through the peak height of the band due to $\mathrm{C}=\mathrm{C}$ stretching (originating from the aromatic from the blue dye) and normalizing with the peak height of the band due to $\mathrm{CN}$ stretching from the raw PAN fiber. The values obtained for the fibers with different thickness dyed with blue dye are in agreement with the quantity of the absorbed dye previously determined from the colorimetric measurements of these fibers: the highest quantity of blue dye is absorbed by the thinnest fiber ( 3 den). However, for a better (more quantitative) correlation between the results obtained from $\mu$-Raman measurements and the methods for determination of the quantity of absorbed dyes, more detailed analysis are needed. This might comprise: a) Larger number of fibers with different thicknesses; b) More precise colorimetric measurements of the adsorbed dye; c) Recording the Raman spectra of fibers at several different wavelengths of the excitation laser source radiation.

Acknowledgements. The authors wish to thank Mrs. Myriam Moreau, from HORIBA Jobin-Yvon, Raman Application Laboratory, for technical assistance in recording $\mu$-Raman spectra of the blue PAN fibers; the financial support from the Ministry of Education and Science of Republic of Macedonia, project No. 05-434, titled: "Application of spectroscopic methods in analysis of automotive topcoats, synthetic and natural fibers" is greatly appreciated; the $\mu$-Raman spectrometer Horiba Jobin-Yvon LabRam 300 at the Institute of Chemistry, Faculty of Natural Sciences and Mathematics in Skopje, Republic of Macedonia has been obtained through the FP6 project "Reinforcement of the Research Capacities of the Spectroscopy Laboratory for Archaeometry" (ForcaSpeclab) financed by the EU Commission.

\section{REFERENCES}

1. V. Causin, Anal. Methods 2 (2010) 792-804.

2. D. Bourgeois and S. P. Church, Spectrochim. Acta A 46 (1990) 295-301.

3. S.P. Bouffard, A. J. Sommer, J. E. Katon, and S. Godber, Appl. Spectrosc. 48 (1994) 1387-1393.

4. I. P. Keen, G. W. White, and P. M. Fredericks, J. Forensic Sci. 43 (1998) 82-89.

5. J. Miller and E. G. Bartick, Appl. Spectrosc. 55 (2001) 1729-1732.

6. I. I. Shamolina, A. M. Bochek, N. M. Zabivalova, D. A. Medvedeva, and S. A. Grishanov, Fibres Text. 11 (2003) 33-38.

7. V. Causin, C. Marega, S. Schiavone, and A. Marigo, Forensic Sci. Int. 151 (2005) 125-131.

8. G. Jochem, R.J. Lehnert, Sci. Justice 42 (2002) 215-221.

9. J. Thomas, P. Buzzini, G. Massonnet, B. Reedy, and C. Roux, Forensic Sci. Int. 152 (2005) 189-197.

10. G. Massonnet, P. Buzzini, G. Jochem, M. Stauber, T. Coyle, C. Roux, J. Thomas, H. Leijenhorst, Z. Van Zanten, K. Wiggins, C. Russell, S. Chabli, A. Rosengarten, J. Forensic. Sci. 50 (2005) 1028-1038.

11. B. Minčeva-Šukarova, B. Mangovska, G. Bogoeva-Gaceva, V. M. Petrusevski, and B. Lendl, in: Proceedings of 4th International Conference on Advanced Vibrational Spectroscopy ICAVS-4, Book of Abstracts, Corfu, Greece, June 2007, p. 190.

12. O. Magdenovska, V. Manevska, and B. Minceva-Sukarova, in: Proceedings of XXth Congress of Chemists and Technologists of Macedonia, Book of Abstracts, Ohrid, Republic of Macedonia, September 2008, p. 317.

13. B. Mangovska, G. Bogoeva-Gaceva, and I. Jordanov, Tekstil 49 (2000) 131-137.

14. I. Smilev, Tekstilna industrija 9-10 (1986) 30-36. 
15. B. Mangovska and L. Djordjevski, Tekstilna Industrija 11-12 (1986) 28-35.

16. LabSpec, Version 5.25.15, 2007.

17. GRAMS Analist ${ }^{\mathrm{TM}}$ for PE 2000 FT-IR, Version 3.01 B, Level II,
Galactic Industries Corp., 1991-1994.

18. J. C. Evans, Spectrochim. Acta 16 (1960) 994-1000.

19. Li-Ling Cho, Forensic Science Journal 6 (2007) 55-62.

20. D. Hadži, Pure Appl. Chem. 11 (1965) 435-453. 